\title{
The LIM and SH3 domain protein family: structural proteins or signal transducers or both? Thomas GP Grunewald ${ }^{1}$ and Elke Butt*2
}

\author{
Address: ${ }^{1}$ Department of Pediatrics, Klinikum rechts der Isar, Technische Universität München, Pediatric Oncology Center, Kölner Platz 1, D- \\ 80804 Munich, Germany and ${ }^{2}$ Institute for Clinical Biochemistry and Pathobiochemistry, University of Wuerzburg, Grombuehlstr. 12, D-97080 \\ Wuerzburg, Germany \\ Email: Thomas GP Grunewald - Thgruenewald@web.de; Elke Butt* - butt@klin-biochem.uni-wuerzburg.de \\ * Corresponding author
}

Published: 17 April 2008

Molecular Cancer 2008, 7:31 doi:10.1 I86/1476-4598-7-31
Received: 4 February 2008

Accepted: 17 April 2008

This article is available from: http://www.molecular-cancer.com/content/7/I/3 I

(c) 2008 Grunewald and Butt; licensee BioMed Central Ltd.

This is an Open Access article distributed under the terms of the Creative Commons Attribution License (http://creativecommons.org/licenses/by/2.0), which permits unrestricted use, distribution, and reproduction in any medium, provided the original work is properly cited.

\begin{abstract}
LIM and SH3 Protein I (LASP-I) was initially identified from a cDNA library of metastatic axillary lymph nodes (MLN) more than a decade ago. It was found to be overexpressed in human breast and ovarian cancer and became the first member of a newly defined LIM-protein subfamily of the nebulin group characterized by the combined presence of LIM and SH3 domains. LASP2, a novel LASPI-related gene was first identified and characterized in silico. Subsequently it proved to be a splice variant of the Nebulin gene and therefore was also termed LIM/nebulette. LASP-I and -2 are highly conserved in their LIM, nebulin-like and SH3 domains but differ significantly at their linker regions. Both proteins are ubiquitously expressed and involved in cytoskeletal architecture, especially in the organization of focal adhesions. Here we present the first systematic review to summarize all relevant data concerning their domain organization, expression profiles, regulating factors and function. We compile evidence that both, LASP-I and LASP-2, are important during early embryo- and fetogenesis and are highly expressed in the central nervous system of the adult. However, only LASP-I seems to participate significantly in neuronal differentiation and plays an important functional role in migration and proliferation of certain cancer cells while the role of LASP-2 is more structural. The increased expression of LASP-I in breast tumours correlates with high rates of nodal-metastasis and refers to a possible relevance as a prognostic marker.
\end{abstract}

\section{Domain organization and functional structure of human LASP-I}

The LASP1 gene was initially identified together with three other genes from a cDNA library of metastatic axillary lymph nodes (MLN) from human breast cancer and therefore called MLN50. All four genes were mapped to chromosomal region 17q11-q21.3, a region known to contain the c-erbB-2 and the BRCA1 oncogene and to be altered in $20-30 \%$ of all breast cancers $[1,2]$. Northern blot analysis revealed that the approximately $4.0 \mathrm{~kb}$ long mRNA of MLN50 is ubiquitously expressed at basal levels in normal tissue and overexpressed in $8 \%$ of all tested human breast cancer tissues (5 of 61). Sequence analysis showed that MLN50 encoded a putative protein of 261 residues containing a LIM motif at its amino terminus and a src homology 3 (SH3) domain at its C-terminal part. This domain organization defined a new LIM protein subfamily characterized by the combined presence of LIM and SH3 domains [1]. MLN50 was termed accordingly: LIM and SH3 Protein 1 - in short LASP-1. 
The LIM domain is an arrangement of eight cysteine and histidine residues $\left(\mathrm{C}-\mathrm{X}_{2}-\mathrm{C}-\mathrm{X}_{16 / 23}-\mathrm{H}-\mathrm{X}_{2}-\mathrm{C}-\mathrm{X}_{2}-\mathrm{C}-\mathrm{X}_{2}-\mathrm{C}-\mathrm{X}_{16}\right.$ $\left.{ }_{21}-\mathrm{C}-\mathrm{X}_{2 / 3}-\mathrm{C} / \mathrm{D} / \mathrm{H}\right)$, is found in a number of vertebrate and invertebrate proteins and known to mediate protein-protein interactions as a modular binding interface $[1,3-5]$. Although no binding partner for the LIM-domain of LASP-1 has been identified so far, the zinc-finger module in the LIM-domain of LASP-1 is a morphologically and perhaps functionally independent folding-unit of this protein harbouring the possibility of direct binding to DNA [6].

The N-terminal LIM domain is followed by two nebulinlike repeats called R1 and R2 each 35 residues long enabling the protein to bind to F-actin. The actin-binding domains of LASP-1 mediate a direct interaction between LASP-1 and actin at cell membrane extensions [7-12]. The binding of LASP-1 to actin stress fibres is mediated through its interaction with palladin that binds to the $\mathrm{SH} 3$ domain of LASP-1. siRNA knock-down of palladin leads to loss of LASP-1 at actin stress fibres and redirection to focal contacts without changing actin filaments. Thus palladin is necessary to recruit LASP-1 to actin stress fibres but not to focal contacts [13].

Via its nebulin-like actin-binding repeats LASP-1 has an additional interaction with kelch related protein 1 (Krp1), a focal adhesion protein involved in pseudopodial elongation and cell migration [14]. The binding between LASP-1 and Krp1 occurs in co-localization to the membrane-bound integrin CD44 and to the adaptor protein Ezrin - both of which mediate the cellular contact to the extracellular matrix and intracellular signal transduction in benign and malign cells [14-16].

The exact cellular function of LASP-1 is not known yet, but the protein has previously been reported to localize within multiple sites of dynamic actin assembly such as focal contacts, focal adhesions, lamellipodia, membrane ruffles, and pseudopodia $[1,8,17-19]$, suggesting that it plays an essential role in actin cytoskeleton organisation at leading edges of migrating cells.

The actin-binding-motifs are followed by a linker-region with several characterized specific phosphorylation residues at serine/threonine and tyrosine that regulate function and localization of the protein. In fact, human LASP1 is phosphorylated by cAMP- and cGMP-dependent protein kinases (PKA and PKG) at serine 146 [9]. In rabbit parietal cells, elevation of intracellular cAMP by forskolin induced a partial translocation of LASP-1 to the apically directed F-actin rich intracellular canaliculus, which is the site of active $\mathrm{HCl}$ secretion $[17,18,20]$. Lack of gastrin stimulation led to decreased LASP-1 phosphorylation and subsequent lack of $\mathrm{HCl}$ secretion without changing total amount of LASP-1 protein [21]. In PTK2 cells, transfected with LASP-1 mutant S146D, the pseudo-phosphorylation resulted in a translocation of the protein from the membrane to the cytosol, followed by reduced cell migration [9].

In contrast to human LASP-1, murine LASP-1 is phosphorylated at threonine 156 by PKA and PKG. Nevertheless, exposure of human and murine mesangial cells to forskolin induced a translocation of both, human and murine LASP-1, from the focal contacts to the cell interior without affecting F-actin structure and a comparison of various murine and human tissues revealed a similar prominent LASP-1 expression (Figure 1) [22]. Altogether, the existing data suggest no functional differences between human and murine LASP-1 [10].

Additionally, human LASP-1 is phosphorylated at tyrosine 171 by Abelson tyrosine kinase [19]. Abelson tyrosine kinase is strongly involved in carcinogenesis of hematopoetic tumours, such as B-cell lymphomas [23]. Phosphorylation at tyrosine 171 is also associated with loss of LASP-1 from focal adhesions and furthermore with the initiation of cell death, but without changes in the dynamics of migratory processes [19].

The C-terminal SH3 motif is a small domain of 60 amino acids, first identified as a conserved sequence in the noncatalytic amino-terminal part of the src protein tyrosine kinase. SH3 domain proteins are usually located close to the plasma membrane, suggesting that the $\mathrm{SH} 3$ domain may be implicated in localizing the protein to this cell compartment [24].

In fact, LASP-1 primarily localizes to focal contacts, but confocal microscopy and Western blot analysis of cytosolic and nuclear preparations of various breast cancer cell lines also confirmed its nuclear localization [25]. Thus, LASP-1 is not exclusively a cytosolic protein, but is also detectable within the nucleus.

At focal adhesions the C-terminal SH3 domain of LASP-1 is involved in protein-protein interactions through binding to proline-rich sequences, specifically with palladin, lipoma preferred partner (LPP), Prointerleukin-16 (ProIL-16), vasodilator stimulated phosphoprotein (VASP) and zyxin $[10,26,27,13]$. Recent data have shown that after photobleaching of cells and subsequent destruction of cytoskeletal networks, the recovery of LASP-1 and LASP-2 occurred from the anterograde direction while actin recovered inwards from the bundle tips, consistent with the retrograde flow by treadmilling. These results suggest that LASP- 1 and - 2 participate in the stabilisation of actin-bundles but not in their initiation [11]. 


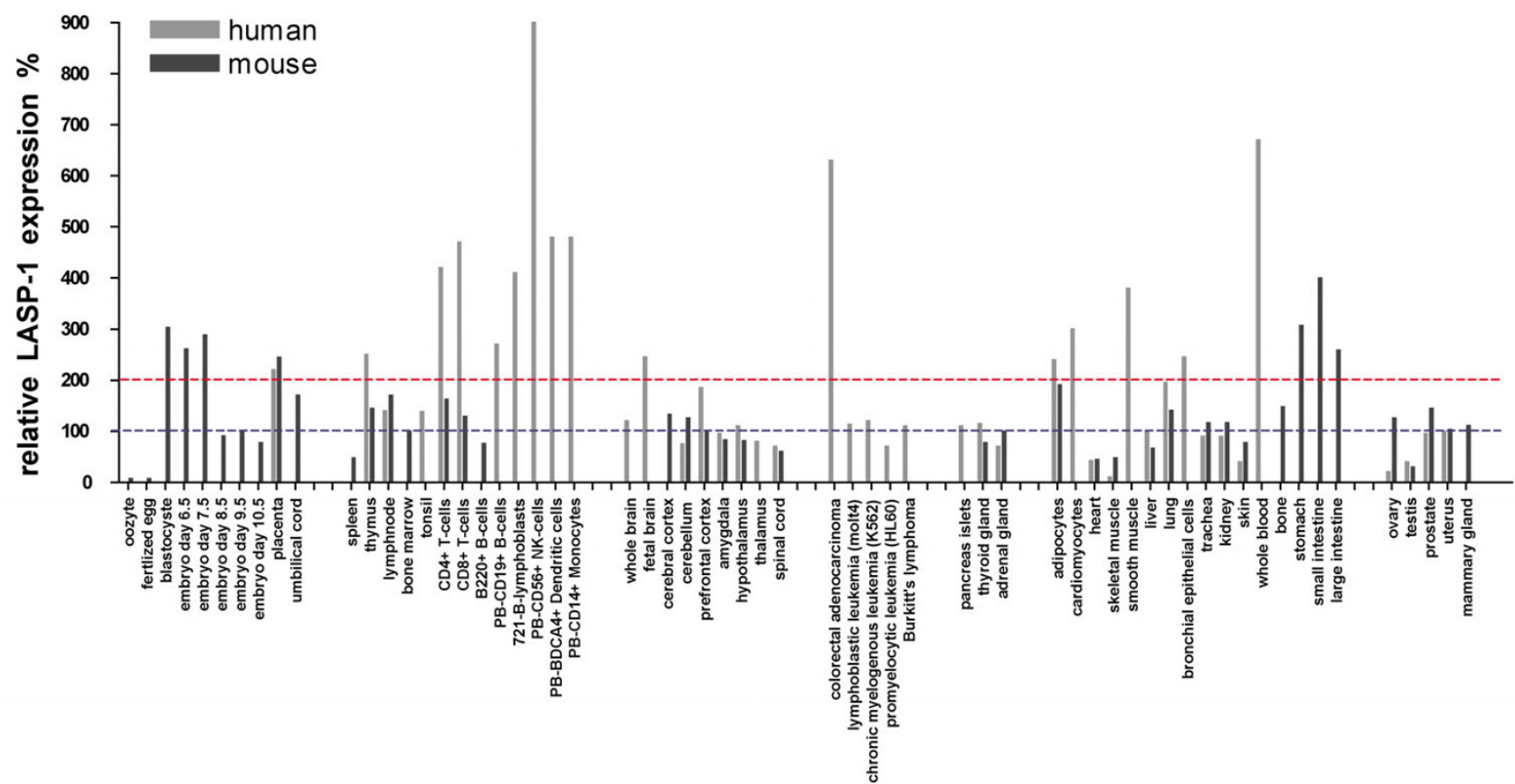

Figure I

Relative expression pattern of murine (black columns) and human (gray columns) LASP-I of selected tissues in part adapted from Su et al. 2002 [22]. The median of LASP-I expression in all tissue types that have been originally analyzed by Su et al. was set at 100\% (blue line); two fold value of the median is indicated in red. As seen in the graph LASP-I is expressed in a wide variety of human and murine tissues. High to excessive expression is observed during early embryonic development, in immunocompetent cells, fetal brains, muscle cells, entire blood and colorectal carcinomas. Interestingly, LASP$I$ is not expressed at high levels in benign tissues of the reproductive tract (ovary and mammary gland), but has been reported to be overexpressed in metastases of malign tumours derived from these tissues.

Invasion assays with a $\triangle \mathrm{SH} 3$ deletion mutant of LASP-1 invariably led to the conclusion that especially its $\mathrm{SH} 3$ domain is necessary for pseudopodial formation, extension and invasion [14,28].

In summary, these multilateral protein-protein interactions mediated by the LIM and SH3 domains can be regarded as scaffolds for the formation of protein complexes of higher order and imply that LASP-1 is an important structural protein of the cytoskeleton (Figure 2 and Table 1).

\section{Domain organization and functional structure of human LASP-2}

A novel LASP1-related gene, LASP2, was identified and characterized by using bioinformatics. The nucleotide sequence of human LASP2 cDNA was determined in silico and the protein (270 aa) showed $97.4 \%$ and $63.7 \%$ totalamino-acid identity with murine LASP-2 and human LASP-1, respectively [29]. Apparent molecular weights of LASP-1 and LASP-2 are $38 \mathrm{kDa}$ and accordingly $34 \mathrm{kDa}$.
LASP2 was found to be a splice variant of the Nebulin gene and was therefore also termed LIM-nebulette. LASP2 has a chimeric gene locus, which might be generated through homologous recombination between the ancestral LASP2-tem7l-cacnb2 locus on chromosome 10q12 and the ancestral nebl-arl8 locus on chromosome 2q23 displaying a classical example for gene fusion during evolution as one of the mechanisms to generate alternative splice variants [29]. In contrast to sarcomeric nebulette, LASP-2 (LIM-nebulette) is also expressed in non-muscle cells. It displays a modular structure with an N-terminal LIM domain, three nebulin-like repeats and a C-terminal SH3 domain and shows high similarity to LASP-1 (Figure 2) $[27,29]$. However, the linker domains differ significantly between LASP-2 and LASP-1 while all other domains are highly conserved in chicken, mouse, and human [30].

Like LASP-1, LASP-2 is also predominantly located at focal contacts via its nebulin like repeats mediating binding to F-actin and targeting the protein to focal adhesions [12]. Co-precipitation experiments and a yeast two-hybrid 


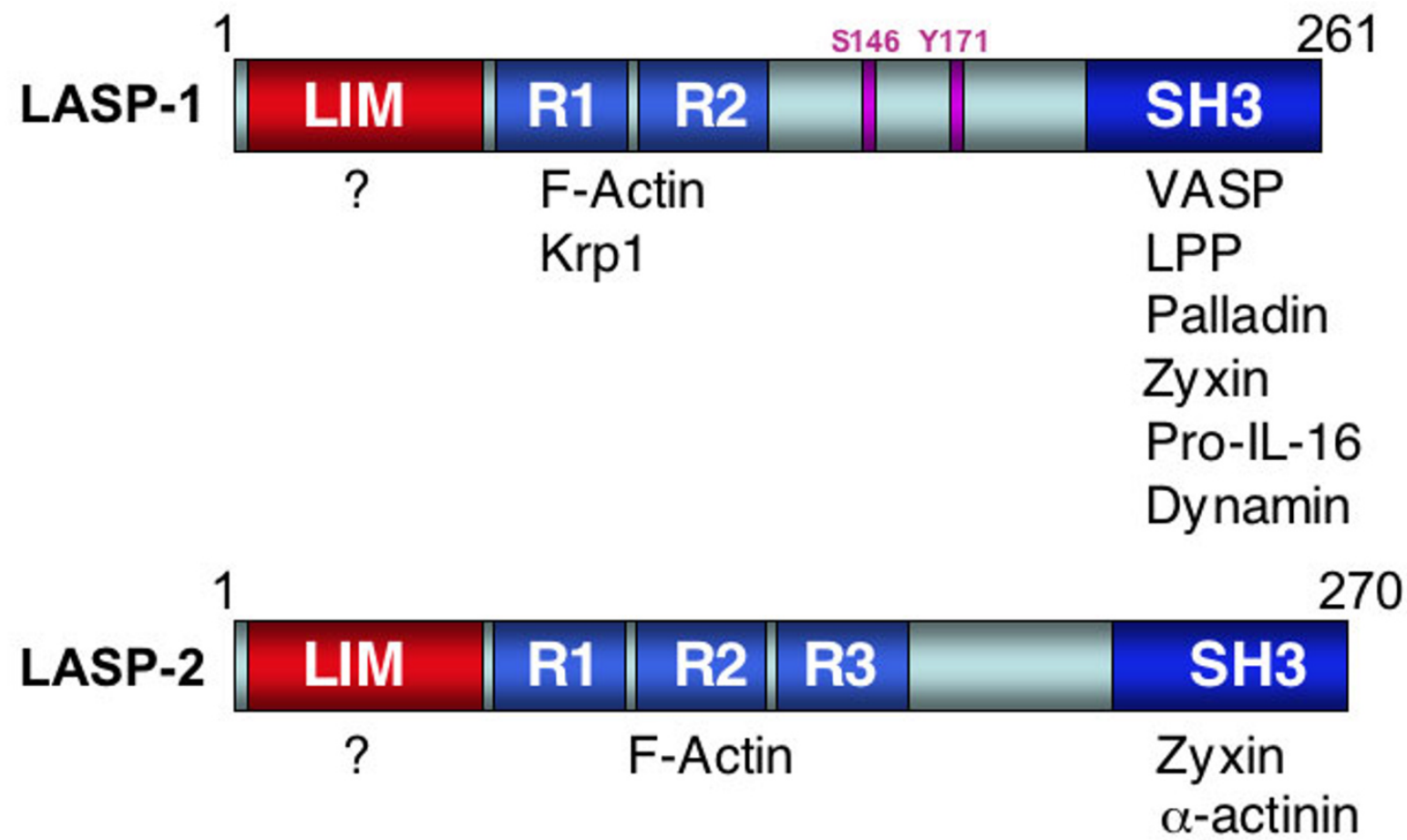

Figure 2

Schematic models of LASP-I and LASP-2 domain structures. Identified binding partners are indicated at the appropriate domains (KrpI - Kelch related protein I, LPP - lipoma preferred partner, VASP - vasodilator stimulated phosphoprotein, Pro-IL-I6 - Prointerleukin- I6). Known phosphorylation sites at serine I46 (SI46) and tyrosine I7I(YI7I) are marked with pink boxes.

screen revealed the specific interaction with zyxin, in which the SH3 domain of LASP-2 is both necessary and sufficient for zyxin binding [27]. LASP-2 shows a subcellular distribution at focal adhesions similar to LASP-1. Thus, both proteins may play an important role in the organization of focal adhesions in cooperation with zyxin [27] which is a key player for correct assembly and disassembly of focal adhesions [31].

The exact cellular function of LASP-2 has not been fully elucidated yet, but the structural differences of LASP-2 in comparison to LASP-1 imply that its function and binding partners might be distinct from those of LASP-1 (Figure 2 and Table 1).

\section{LASP-I and LASP-2 in invertebrates}

Genes encoding proteins homologous to LASP1 and LASP2 were also found in gene-databases of invertebrates such as sea urchin, nematodes and insects. Recently, Terasaki et al. described and characterized LASP in the ascidian Ciona intestinalis [32]. Multiple alignments between vertebrate and invertebrate LASP-proteins demonstrated a high homology of their domains and the strong expression of putative ancestral LASP in neural lineage cells and the nerve cord of Ciona intestinalis is similar to the high expression of LASP- 1 and -2 in the CNS of vertebrates [32]. The phylogenetic analysis suggests that the LASP1 and LASP2 genes might have been generated during evolution from invertebrates to vertebrates.

LASP-I and LASP-2 are ubiquitously expressed and crucial for cellular development and differentiation in vertebrates Human LASP1 and LASP2 are located on chromosome $17 \mathrm{q} 12$ and $10 \mathrm{p} 12 / 2 \mathrm{q} 23$, respectively $[2,29]$. The murine gene of LASP1 was mapped by in situ hybridization to the $11 \mathrm{C}-11 \mathrm{D}$ region on chromosome 11 . The isolation and characterization of murine LASP1 cDNA showed that it is highly conserved with its human counterpart. Sequence alignment revealed a high level of identity of LASP1 and LASP2 genes across species barriers [33].

The murine gene is expressed at basal levels in almost all adult tissues and at high levels during murine embryogenesis from blastocyste stage to day 17.5 as shown by Microarray and Northern blot analysis [22,34], indicating an 
Table I: Summary of putative and potential functions of LASP-I and LASP-2

\begin{tabular}{|c|c|c|c|}
\hline protein & localization & putative and potential function & reference(s) \\
\hline \multirow[t]{11}{*}{ LASP-I } & focal contacts & signal transducer for IGF-I & {$[49]$} \\
\hline & & zyxin recruiting protein & {$[38,39]$} \\
\hline & & modulator of migration and pseudopodial elongation & {$[19,25,38,39,46,47]$} \\
\hline & & interaction partner for cytoskeletal organisation & {$[7,8,10,11,13,14,26,27]$} \\
\hline & & stabilisation of actin filament bundles & {$[11]$} \\
\hline & & modulator of active $\mathrm{HCl}$ secretion in gastric parietal cells & {$[17,18,20,21,70]$} \\
\hline & nucleus & modulator of proliferation in concert with other proteins & {$[25,38,39]$} \\
\hline & & cell-cycle-control & {$[26,38,39]$} \\
\hline & & (transcription factor) & {$[6,25]$} \\
\hline & postsynaptic/CNS & axonal growth and differentiation/structural protein/autism linked gene & {$[40,42]$} \\
\hline & Z-discs/A-bands & structural protein (possibly function in myofilament stabilization and assembly) & {$[12]$} \\
\hline \multirow[t]{4}{*}{ LASP-2 } & focal contacts & interaction partner for cytoskeletal organisation & {$[27,30]$} \\
\hline & & stabilisation of actin filament bundles & {$[11]$} \\
\hline & Z-discs & structural protein/myofilament stabilization and assembly & {$[12,37]$} \\
\hline & CNS & unclear/structural protein & [30] \\
\hline
\end{tabular}

essential role of LASP1 in cellular migration and differentiation (see also Figure 1).

Suitably, LASP1 was characterized as one gene out of six inserted into a $185-\mathrm{kb}$ contig sequence flanking a transgene on distal murine chromosome 11 that caused a recessive phenotype with skeletal malformation [35]. A comparison with the corresponding LASP1 region on human chromosome $17 \mathrm{q} 12$ revealed several small-scale rearrangements during evolutionary divergence within this cluster of densely packed genes, hinting to a crucial function of LASP-1 in embryo- and fetogenesis [35]. In further support of this hypothesis it has been shown that human mesenchymal stem cells start to express LASP-1 in parallel to acquiring the capacity for osteogenic differentiation [36].

\section{LASP-I and -2: interaction with the cytoskeleton}

LASP-1 and LASP-2 are actin-binding scaffolding proteins [8]. LASP-1 has been reported to regulate cell migration, proliferation and to localize at focal adhesions, along stress fibres and leading edges like lamellipodia, filopodia and pseudopodia $[8,9]$. LASP-2 co-localizes to actin filament bundles in neuronal cell lines [30] as well as in focal adhesions and at intercalated discs in cardiac myocytes [37].

During cell migration actin is supplied to the extending lamellipodia tips to push the cell forward thereby producing a retrograde flow. This process was revealed by fluorescence recovery after photobleaching (FRAP) with eGFPactin as well as eGFP-LASP-1 and -2. During the rapid process of exchanging actin bundles LASP-1 and -2 recover from the anterograde direction over actin bundles into the tips of lamellipodia. In addition, a lateral crosslinking of actin filaments by LASP- 1 and -2 is visible sug- gesting a participation in stabilisation of actin bundles [11].

When expressed as a truncated form (LASP-1 $\Delta$ SH3) LASP1 remains co-localized with F-actin at the tips of pseudopodia but pseudopodia elongation is suppressed demonstrating the important role of LASP-1 in cell motility [14]. Whether this effect is solely dependent on LASP-1 dysfunction or the disrupted binding of the $\mathrm{SH} 3$ domain interacting partners remains to be elucidated.

In non-motile serum-starved cells, LASP-1 is localized to the peripheral edge of the cell. Exposure of the cells to growth factors that activate cell migration caused a rapid (1-2 min) relocalisation of LASP-1 from the periphery to focal adhesions and later on (>15 min) to actin-rich membrane ruffles on the cell surface [11]. Interestingly, depletion of LASP-1 did not cause differences in adhesion and spreading of the cells but significantly reduced the ability of the cells to migrate $[19,38,39]$. Phosphorylation of LASP-1 at tyrosine 171 by Abl-kinase prevents translocation of LASP-1 to focal contacts [19] while phosphorylation at serine 146 by PKA renders the protein more cytosolic [9].

In striated muscle cells LASP-1 localizes to A-bands and Zdiscs implying a role for LASP- 1 as a structural protein in contractile cells [12]. Consistently a high expression of LASP-1 was observed in human vascular smooth muscle cells and myoepithelial cells of mammary glands $[38,39]$.

Recently, LASP-2 was detected in heart and skeletal muscle [37]. The protein crosslinks and organizes actin filaments into bundles and directly interacts with the Z-disc protein $\alpha$-actinin $[12,37]$ suggesting a crucial role in myofilament assembly and stabilisation (Table 1). In contrast 
to LASP-1, LASP-2 is not detectable at A-bands of striated muscle cells. This disparity in localization might be due to specific structural differences in the linker regions and number of nebulin repeats of these proteins [12] (Figure 2).

\section{LASP-I and LASP-2 are highly expressed in the central nervous system}

Both, LASP-1 and - 2 are highly present in the central nervous system as they are prominently expressed in the fetal and adult brain. Compared to LASP-2, which additionally is highly expressed in striated muscle cells, LASP-1 displays a broader expression pattern also among various non-muscle tissues [30,37,40,41] (Figure 1).

As expected from its structural similarity to LASP-1, LASP2 possesses actin-binding activity and co-localizes with actin filaments in filopodia of neuroblastoma cells [30].

LASP-1 is expressed in cortex, hippocampus, cerebellum and densely concentrated at the postsynaptic membrane of dendritic spines $[40,41]$. Although the exact function of LASP-1 in CNS is still unclear a region on chromosome 17 has recently been highlighted in multiple studies as being linked to autism (MIM [209850]). A dense panel of single nucleotide polymorphisms (SNPs) was selected across the linkage peak and analyzed in a trio-based study design. Nominally significant single SNPs and/or haplotypebased association results were detected in 15 genes, of which, MYO1D, ACCN1 and LASP1 stand out as genes with autism risk alleles [42].

Moreover, analysis of the molecular signature in neurons under homocysteic acid induced neuronal stress revealed, that, together with several other proteins well known as risk factors in schizophrenia and neurodegeneration, LASP-1 was modified by phosphorylation. Homocysteic acid induces calcium influx into neurons. On the molecular level this is correlated with fast modification of proteins like phosphorylation and proteolysis. Thus the observed phosphorylation suggests a role of LASP-1 in homocysteic acid induced neurotoxicity [43].

Furthermore, during early differentiation of cultured hippocampal cells LASP-1 initially localizes mainly at the leading sites of growth cones but distributes immediately along the dendritic membranes and subsequently clusters at postsynaptic densities of dendritic spines [40]. Consistently, LASP1, but not LASP2, belongs to a group of several strongly upregulated genes in response to nerve growth factor $(\beta-\mathrm{NGF})$ stimulation in phaeochromocytomal PC12 cells, which are commonly used as a cell model for neurite outgrowth [44]. These data indicate that in particular LASP-1 is involved in neuronal differentiation and development (Table 1 and 2).

\section{LASP-I within gastric parietal cell $\mathrm{HCl}$ secretion}

LASP-1 is widely distributed among various secretory tissues e.g. in epithelial cells of the kidney, in ductal cells of the exocrine pancreas and in gastric parietal cells (Figure 1) [17]. The resting parietal cells contain membranous tubules and vesicles that represent the storage depot of the $\mathrm{H}^{+} / \mathrm{K}^{+}$-ATPase proton pump. Upon stimulation the tubulovesicles fuse with the apical membrane for $\mathrm{HCl}$ secretion [20]. In unstimulated gastric parietal cells LASP-1 is localized at the cell cortex (basolateral region). Histamine induced phosphorylation of LASP-1 by PKA induced a partial redistribution of LASP-1 from the cortical membrane to the actin enriched apically-directed intracellular tubuli, the site of active proton transport $[8,18]$. Movement of the vesicles is in part controlled by dynamin, a large GTPase that regulates the fusion of vesicles with the plasma membrane. In this context, LASP-1 has been identified as a dynamin binding protein implying a regulatory function of LASP-1 in $\mathrm{HCl}$ secretion by linking the vesicular trafficking machinery with the cytoskeleton [20] (Table 1).

\section{LASP-I is over-expressed in human breast and ovarian cancer}

LASP-1 expression has been reported to be increased in metastatic breast and ovarian cancer, suggesting that overexpression of LASP-1 may be involved in the migratory process of cancer cells $[1,25]$. Knock-down of LASP- 1 by RNA-interference in metastatic breast and ovarian cancer cell lines did not lead to induction of apoptosis or necrosis but to strong inhibition of migration and proliferation with cell cycle arrest in G2-phase, while artificial overexpression of LASP-1 in non-neoplastic PTK2 cells resulted in a dramatic acceleration of migration [38,39]. These observations are supported by a case-control study correlating the histological scored expression level of LASP-1, with standard clinicopathological parameters. In this report, LASP-1 expression was significantly higher in invasive human breast carcinomas compared to fibroadenomas with strong cytoplasmatic staining for LASP-1 in $55.4 \%$ of the invasive tumours. Although levels of LASP-1 expression did not correlate with histological tumour grading, c-erbB2-, estrogen- or progesterone-expression they did correlate significantly with increased tumour size and rate of nodal-positivity. These data indicate an important role of LASP-1 in proliferation and migration of ovarian and breast cancer cells [25].

In a bovine mammary gland model system, microarray experiments yielded many interesting genes exhibiting differential expression in developing and/or lactating mammary tissue, including oncogenes (VAV3, C-myc), mediators of apoptosis (Caspase 8), and LASP-1 [45]. Thus we assume that LASP-1 might as well be necessary 
Table 2: Differential expression of LASP-I in various cell types and known regulators and modifiers of LASP-I-expression

\begin{tabular}{|c|c|c|c|c|c|}
\hline \multicolumn{6}{|c|}{ LASP-I upregulation } \\
\hline species & cell type & modifier/stimulus & fold & method & ref. \\
\hline bovine & breast epithelium & lactating mammary tissue & $>18$ & cDNA-Microarray & [45] \\
\hline \multirow[t]{6}{*}{ mouse } & prostatic adenocarcinma & Neu (erbB2)-overexpression & 3.8 & cRNA-Microarray & [7I] \\
\hline & RAW264.7 macrophages & treatment with LPS & 3.37 & cDNA-Microarray & [72] \\
\hline & pluripotent mesenchymal $\mathrm{C} 3 \mathrm{H} / 10 \mathrm{TI} / 2$ cells & $\begin{array}{l}\text { activation of Sonic Hedgehog signalling } \\
\text { cascade }\end{array}$ & 1.9 & cDNA-Microarray & [53] \\
\hline & interstitial cells of Cajal & comparison to tunica muscularis & 1.89 & cDNA-Microarray & [73] \\
\hline & embryonic fibroblasts & overexpression of IGF-receptor & 1.6 & Northern Blots & [49] \\
\hline & FDBI myeloic leukaemia cells & GM-CSF & 1.5 & QRT-PCR & [74] \\
\hline \multirow[t]{9}{*}{ human } & chronic myeloid leukaemia K562 cells & stimulation of cells with haemin & 8 & cDNA-Microarray & [75] \\
\hline & BT-474 breast cancer cells & LASPI gene amplification (8x) & $\approx 8$ & Northern Blots & [2] \\
\hline & promyelocytic leukaemia HL60 cells & I'-25'-dihydroxy-cholecalciferole & 4.97 & cDNA-Microarray & [76] \\
\hline & podocytes & Wilms tumour suppressor I mutation & 3.3 & 2D-DIGE & [28] \\
\hline & HEK 293 cells & overexpression of HNF4 $\alpha$ & 2.8 & cDNA-Microarray & [77] \\
\hline & $\begin{array}{l}30 \text { different commercial and primary breast } \\
\text { cancer cell lines }\end{array}$ & gain on $17 q 12$ & $>2$ & cDNA-Microarray & [78] \\
\hline & E-cadherin mutation & Wnt activity & 1.89 & cDNA-Microarray & [47] \\
\hline & MDA-MB435S breast cancer cells & E-cadherin mutation & 1.77 & cDNA Microarray & [47] \\
\hline & MCF-7 breast cancer cells & Insulin like growth factor (IGFI) & 1.6 & cDNA-Microarray & [49] \\
\hline porcine & primary retinal Müller glia cells & in vitro conditions & 6.6 & 2D-Gel/Mass Spectrometry & [79] \\
\hline \multirow[t]{3}{*}{ rat } & periaqueductal grey cells & $\begin{array}{l}\text { reduced exploratory activity in the } \\
\text { elevated plus maze }\end{array}$ & 3.41 & cDNA-RDA & [80] \\
\hline & phaeocytochromal PCI 2 cells & NGF induced $\mathrm{SH} 2 \mathrm{~b} / \beta$-activity & 3.3 & cRNA-Microarray & [44] \\
\hline & alevolar macrophages CRL-2192 & pseudohypoxia induced by bismuth & 2.1 & cDNA-Microarray & [81] \\
\hline \multicolumn{6}{|c|}{ LASP-I downregulation } \\
\hline species & cell type & stimulus & fold & technique & ref. \\
\hline \multirow[t]{3}{*}{ mouse } & hindbrain & model for smith-lemli-opitz-syndrome & -3.24 & cRNA-Microarray & [82] \\
\hline & mammary epithelium & Prolactin receptor knockout & -1.24 & cDNA-Microarray & {$[83]$} \\
\hline & murine embryonic fibroblasts & $\begin{array}{l}\text { oncogenic RAS expression in absence of } \\
\text { p53 }\end{array}$ & n.d. & cDNA-Microarray & [84] \\
\hline \multirow[t]{2}{*}{ human } & chondrocytes & proinflammatory cytokine IL-I $\beta$ & -2.3 & cDNA-Microarray & [85] \\
\hline & mulitiple myeloma (MM) & transition from MGUS to MM & -1.91 & cDNA-Microarray & [86] \\
\hline
\end{tabular}

for proliferation of epithelial cells during physiological human breast development and lactation.

During recent years LASP1 was identified in several microarray studies that analysed genes associated with tumour development and cancer progression (overview given in Table 2).

LASP-1 is differentially up regulated in several breast cancer cell lines with E-cadherin-mutations and subsequent accelerated migration. E-cadherin is a cell-cell adhesion molecule and tumour invasion suppressor gene frequently altered in human cancers. Through its cytoplasmic domain it interacts with beta-catenin which in turn interacts with the WNT (wingless) signalling pathway affecting a number of target genes - among them LASP1 $[46,47]$. Anti-WNT1 monoclonal antibodies show promising in vitro effects in cancer treatment [48], maybe medi- ated through down regulation of LASP-1 and other proteins enhancing anchorage independent migration.

A recent study identified genes associated with insulinlike growth factor-I receptor (IGF-IR)-mediated cellular transformation. In cells overexpressing the IGF-IR, LASP-1 is also overexpressed. MCF-7 breast cancer cells treated with IGF-I exhibit upregulated expression of LASP-1 as well. Expression induction required the activation of the PI3-kinase signalling pathway, suggesting that LASP-1 may mediate IGF-IR function in cancer progression and operates as a signal transducer [49].

In a study, which established a prognostic index for nodalpositive breast cancer, all 20 patients were LASP1 positive only differing in mRNA expression levels [50]. However, in patients that died within 5 years after surgery LASP1 
was found to be one out of five genes with decreased expression levels.

Several additional observations underscore the important role of LASP-1 in cancer: Altered LASP-1 expression was associated with the MLL gene in acute myeloid leukemia through forming a new translocation-gene of the LASP1 and $M L L$ gene in a patient with a high risk of stratification. In this patient two different versions of this new fusion gene $\mathrm{t}(11 ; 17)(\mathrm{q} 23 ; \mathrm{q} 12-21)$ were identified: a $5{ }^{\prime} \mathrm{MLL}$ 3 'LASP1 and the reciprocal 5' $L A S P 1-3$ 'MLL translocationgene $[51,52]$.

LASP-1 is also transcriptionally upregulated in response to the morphogen Sonic Hedgehog [53] (Table 2). Disruption of the Hedgehog signalling cascade leads to a number of developmental disorders and plays a key role in the formation of a wide range of human cancers [54].

\section{LASP-I binds to LPP and zyxin and is localised in the nucleus}

In a recent paper variable expression of LASP-1 in breast cancer was detected. In addition to the reported localization at focal contacts and in the tops of lamellipodia, the authors observed a perinuclear and nuclear distribution of the protein [25]. However, sequence analysis revealed no nuclear localization signal for the classical nuclear import pathway. On the other hand, the zinc-finger containing LIM-domain of LASP-1 offers the possibility of direct binding to DNA [6] and LASP-1 may even form heterodomains to become a nuclear transcription factor [55]. Therefore, LASP-1 binding partners might transport the protein from the cytoplasm to the nucleus.

LASP-1 interacts with LPP, a shuttle protein and transcription factor that transduces signals from focal contacts to the nucleus [10]. LPP is a known interaction partner of the tumour suppressor protein Scrib and both proteins colocalize in cell-cell contacts. This interaction links Scrib to a communication pathway between cell-cell contacts and the nucleus, and implicates LPP in Scrib-associated functions. In various benign and malignant tumours, LPP is present in a mutant form, which permanently resides in the nucleus $[56,57]$. Although the role of this interaction between LASP-1 and LPP is still unclear, LASP-1 might be embedded into this novel signalling cascade for tumour growth and migration.

In this context it is interesting to note that also the LASP1 binding partner zyxin has been identified as a differentially transcribed gene in several types of cancer by microarray technology [58].

Zyxin is localized primarily at focal adhesion plaques and is crucial for actin filament polymerization in mammalian cells but also has the ability to shuttle into the nucleus like LPP [31,59].

Silencing of zyxin in HeLa cells resulted in a significant reduction of actin stress fibers [60] whereas under cyclic stretch zyxin only dissociated from focal contacts and accumulated in the nucleus, without affecting vinculin or actin filaments [61]. In genetically zyxin-deficient fibroblasts, the cells display deficits in actin cytoskeleton remodeling [62].

LASP-1 silencing in human breast and ovarian cancer cells led to a diffuse cytoplasmic localization of zyxin without protein loss and without changes in neither vinculin distribution nor actin stress fiber organization, emphasizing the importance of LASP-1 for binding and recruiting zyxin to focal adhesions [38,39].

The loss of zyxin at the sites of focal contacts without changing cellular zyxin protein levels is not restricted to cancer cells but was also observed in human umbilical vein endothelial cells [38]. Interestingly, in these cells zyxin could still be detected along the actin stress fibres, indicating the potential existence of another zyxin-recruiting protein along actin stress fibres [8,9].

In zyxin knock-down experiments neither changes in LASP-1 localization, actin cytoskeleton nor vinculin distribution were detectable indicating that zyxin alone does not change focal adhesion morphology [39]. This is concordant with the fact, that genetically zyxin-deficient fibroblasts even show enhanced adhesion to surfaces and increased integrin expression [62]. In synopsis, LASP-1 and zyxin silencing studies have demonstrated that LASP1 is necessary and sufficient for recruiting zyxin to focal contacts [38,39] (Table 1).

The decreased cell motility after LASP-1 silencing can be explained by the functional loss of zyxin as a scaffolding protein that facilitates the formation of molecular complexes to promote site-specific actin assembly required for cell migration. This is in agreement with previous findings using a non-genetic approach by injecting a peptide derived from the N-terminus of zyxin to displace zyxin from its normal subcellular location and thus leading to reduced cell migration [63]. On the other hand, the siRNA mediated knock-down of zyxin in SKOV-3 cells had no influence on cell migration [39] while genetically zyxindeficient fibroblasts displayed enhanced migration [62]. To date these disparate effects have not been fully elucidated but may be due to specific cellular features.

Zyxin also shuttles through the nucleus - most likely by association with other LIM-proteins - and regulates gene transcription $[55,59,64]$. During mitosis, a fraction of 
zyxin associates with the tumour suppressor h-warts (LATS1) at the mitotic apparatus [65]. H-warts (LATS1) is a key player in mitosis in mammalian cells and loss of its function disrupts normal cell cycle regulation possibly leading to tumor development [66]. In BT-20, MCF-7 and SKOV-3 cells transfected with LASP-1 specific siRNA, zyxin has been shown to dissociate from focal adhesion plaques and to distribute diffusely into the cytoplasm. It is therefore likely that part of zyxin enters the nucleus, binds to h-warts and leads to G2 cell cycle arrest and inhibition of proliferation as observed after LASP-1 silencing [38,39].

When located at focal contacts, zyxin enhances cell migration [63]. Therefore it is conceivable, that tumour cells overexpressing LASP-1 could recruit more zyxin to focal contacts and thereby contribute to accelerated proliferation and migration of these cells, as higher LASP-1 expression, indeed correlates with metastatic stage and tumour size of human breast cancer [25]. A schematic illustration of this hypothetical functional aspect of LASP-1 is depicted in Figure 3.

Interestingly, in Ewing tumor cells zyxin is only expressed at very low levels and remains diffusely distributed throughout the cytoplasm instead of concentrating in actin-rich dynamic structures. Zyxin gene transfer into EWS-FLI1-transformed fibroblasts leads to inhibition of anchorage independent tumor growth, indicating that zyxin has tumor suppressor activity in these cells [67].

Furthermore, LASP-1 interacts via its SH3-domain with Prointerleukin-16 (Pro-IL-16) [26]. Pro-IL-16 is expressed in both, nucleus and cytoplasm of T cells. Cytoplasmic Pro-IL-16 serves as precursor for mature IL-16 while nuclear pro-IL-16 is associated with G0/G1 cell cycle arrest and with T lymphocyte cell cycle growth suppression [68] indicating a potential role for LASP-1 in modifying T lymphocyte proliferation since it is highly expressed in T-lymphocytes as well [22] (Table 1 and Figure 1)

\section{Conclusion}

To date, an ensemble of more than 50 different structural proteins have been identified that orchestrate the rate and organization of actin polymerization and focal adhesion turnover in protrusion. Moreover, there is a growing number of proteins, that have a dual function in serving as a structural and signalling protein [69]. There are several lines of evidence for LASP-1 being such a dual protein. On the one hand it binds to F-actin and is involved in actin-bundle stabilization [7-9,11], but then shuttles to the nucleus and interacts with LPP [10] and zyxin [27] implying a function in modulating their signalling pathways.
The high degree of structural and amino acid identity between LASP-1 and LASP-2 would suggest that both proteins are functionally redundant, particularly because both proteins are strongly expressed during early embryoand fetogenesis. However, after expansive study of the literature we conclude that, despite their similarities, LASP1 and LASP-2 have distinct functions. Although both proteins are expressed in high levels in the CNS, only LASP-1 seems to be significantly involved in neuronal differentiation upon growth factor stimulation and appears to be of importance in epithelial cancer development regarding tumour cell migration and proliferation.

Further studies will be necessary to define the exact physiological functions and to delineate more the differences in function between these highly homologous proteins.

\section{Competing interests}

The authors declare that they have no competing interests.

\section{Authors' contributions}

TG drafted and wrote the paper, designed the tables and the figures. EB corrected and finalized the manuscript. Both authors read and approved the final manuscript

\section{Acknowledgements}

In particular, we thank Barbara Lechner, Ulrike Kämmerer and Veit Buchholz for their helpful commentary and critical reading of the manuscript. EB is funded by Deutsche Krebshilfe (Grant no. 107706).

\section{References}

I. Tomasetto C, Moog-Lutz C, Regnier CH, Schreiber V, Basset P, Rio MC: Lasp-I (MLN 50) defines a new LIM protein subfamily characterized by the association of LIM and SH3 domains. FEBS Lett 1995, 373(3):245-249.

2. Tomasetto C, Regnier C, Moog-Lutz C, Mattei MG, Chenard MP, Lidereau $R$, Basset $P$, Rio MC: Identification of four novel human genes amplified and overexpressed in breast carcinoma and localized to the q I -q2 I.3 region of chromosome 17. Genomics 1995, 28(3):367-376.

3. Sanchez-Garcia I, Rabbitts TH: The LIM domain: a new structural motif found in zinc-finger-like proteins. Trends Genet 1994, 10(9):315-320.

4. Bach I: The LIM domain: regulation by association. Mech Dev 2000, 9 I (I-2):5- 17.

5. Dawid IB, Breen JJ, Toyama R: LIM domains: multiple roles as adapters and functional modifiers in protein interactions. Trends Genet 1998, I4(4): I56-162.

6. Hammarstrom A, Berndt KD, Sillard R, Adermann K, Otting G: Solution structure of a naturally-occurring zinc-peptide complex demonstrates that the $\mathrm{N}$-terminal zinc-binding module of the Lasp-I LIM domain is an independent folding unit. Biochemistry 1996, 35(39): 12723-12732.

7. Schreiber V, Moog-Lutz C, Regnier CH, Chenard MP, Boeuf H, Vonesch JL, Tomasetto C, Rio MC: Lasp-I, a novel type of actin-binding protein accumulating in cell membrane extensions. Mol Med 1998, 4(10):675-687.

8. Chew CS, Chen X, Parente JA Jr., Tarrer S, Okamoto C, Qin HY: Lasp- $I$ binds to non-muscle $F$-actin in vitro and is localized within multiple sites of dynamic actin assembly in vivo. J Cell Sci 2002, I I 5(Pt 24):4787-4799.

9. Butt E, Gambaryan S, Gottfert N, Galler A, Marcus K, Meyer HE: Actin binding of human LIM and $\mathrm{SH} 3$ protein is regulated by cGMP- and CAMP-dependent protein kinase phosphorylation on serine I46. J Biol Chem 2003, 278(18): I560I-I5607. 

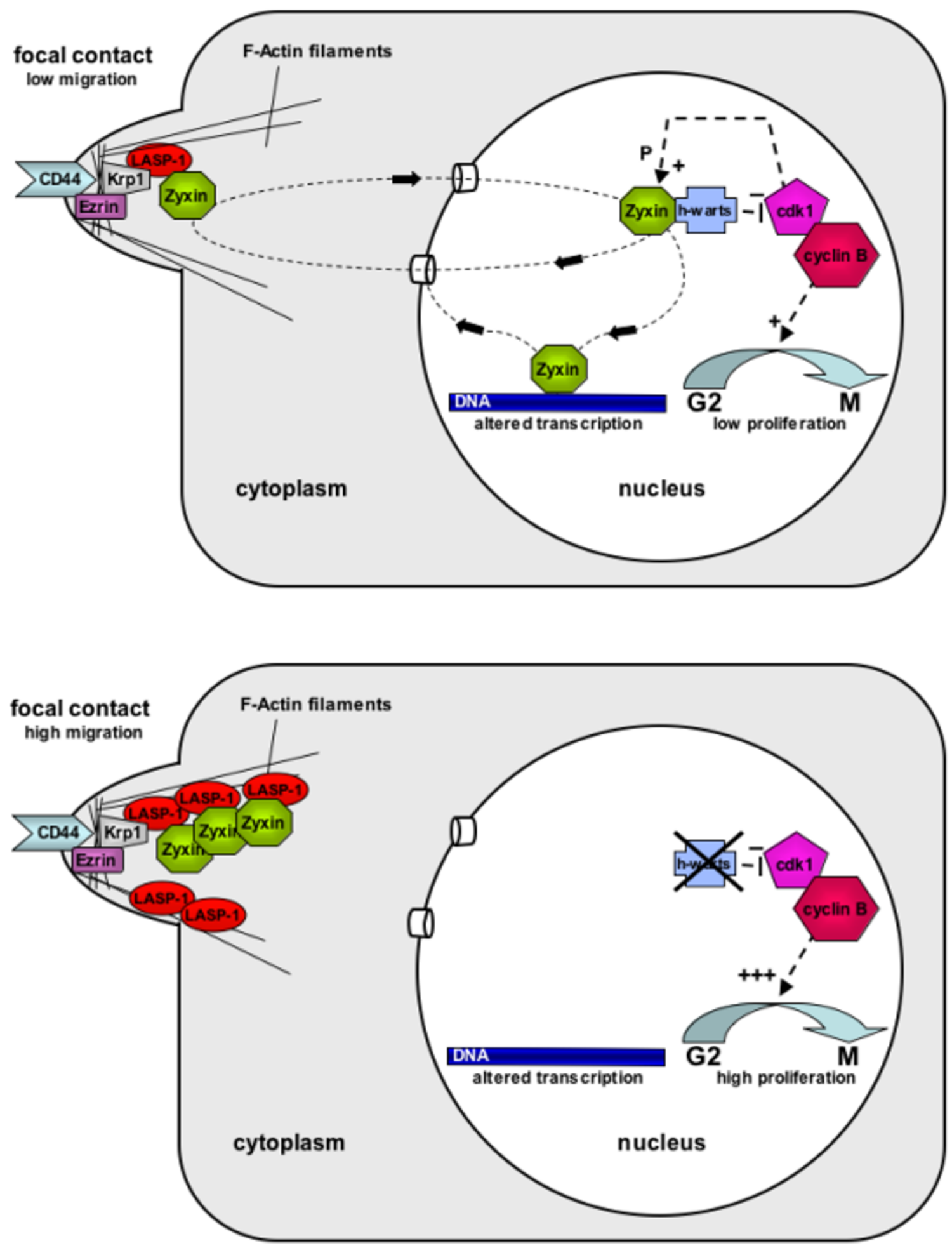

Figure 3

Model of the putative function of LASP-I as a zyxin recruiting protein. Upper panel: physiological situation with normal LASP-I expression. Lower panel: pathological situation in an LASP-I overexpressing cell and subsequent disruption of zyxin signalling. CD44 and Ezrin are integrated into this figure as possible upstream interaction partners because of their close colocalization to LASP-I and Krpl, albeit neither direct nor indirect interaction has been proved yet. 
10. Keicher C, Gambaryan S, Schulze E, Marcus K, Meyer HE, Butt E: Phosphorylation of mouse LASP-I on threonine 156 by cAMP- and cGMP-dependent protein kinase. Biochem Biophys Res Commun 2004, 324(I):308-316.

II. Nakagawa H, Terasaki AG, Suzuki H, Ohashi K, Miyamoto S: Shortterm retention of actin filament binding proteins on lamellipodial actin bundles. FEBS Lett 2006, 580(13):3223-3228.

12. Panaviene $Z$, Moncman $C L$ : Linker region of nebulin family members plays an important role in targeting these molecules to cellular structures. Cell Tissue Res 2007, 327(2):353-369.

13. Rachlin AS, Otey CA: Identification of palladin isoforms and characterization of an isoform-specific interaction between Lasp-I and palladin. J Cell Sci 2006, I I 9(Pt 6):995-I004.

14. Spence HJ, McGarry L, Chew CS, Carragher NO, Scott-Carragher LA, Yuan Z, Croft DR, Olson MF, Frame M, Ozanne BW: AP-I differentially expressed proteins $\mathrm{Krpl}$ and fibronectin cooperatively enhance Rho-ROCK-independent mesenchymal invasion by altering the function, localization, and activity of nondifferentially expressed proteins. Mol Cell Biol 2006, 26(4): 1480-1495.

15. Naor D, Sionov RV, Ish-Shalom D: CD44: structure, function, and association with the malignant process. Adv Cancer Res 1997, 7I:24I-3I9.

16. Sato N, Funayama N, Nagafuchi A, Yonemura S, Tsukita S, Tsukita S: A gene family consisting of ezrin, radixin and moesin. Its specific localization at actin filament/plasma membrane association sites. J Cell Sci 1992, I03(Pt I):|3|-|43.

17. Chew CS, Parente JA Jr., Zhou C, Baranco E, Chen X: Lasp-I is a regulated phosphoprotein within the CAMP signaling pathway in the gastric parietal cell. Am J Physiol 1998, 275(I Pt I): $C 56-67$

18. Chew CS, Parente JA Jr., Chen X, Chaponnier C, Cameron RS: The LIM and SH3 domain-containing protein, lasp-I, may link the cAMP signaling pathway with dynamic membrane restructuring activities in ion transporting epithelia. J Cell Sci 2000 , I I 3 (Pt I I):2035-2045

19. Lin YH, Park ZY, Lin D, Brahmbhatt AA, Rio MC, Yates JR 3rd, Klemke RL: Regulation of cell migration and survival by focal adhesion targeting of Lasp-I. J Cell Biol 2004, 165(3):42 I-432.

20. Okamoto CT, Li R, Zhang Z, Jeng YY, Chew CS: Regulation of protein and vesicle trafficking at the apical membrane of epithelial cells. J Control Release 2002, 78(I-3):35-4I.

21. Jain RN, Brunkan CS, Chew CS, Samuelson LC: Gene expression profiling of gastrin target genes in parietal cells. Physiol Genomics 2006, 24(2): 124-132.

22. Su Al, Cooke MP, Ching KA, Hakak Y, Walker JR, Wiltshire T, Orth AP, Vega RG, Sapinoso LM, Moqrich A, Patapoutian A, Hampton GM, Schultz PG, Hogenesch JB: Large-scale analysis of the human and mouse transcriptomes. Proc Natl Acad Sci U S A 2002, 99(7):4465-4470.

23. Jumaa $\mathrm{H}$, Hendriks $\mathrm{RW}$, Reth $\mathrm{M}$ : $\mathbf{B}$ cell signaling and tumorigenesis. Annu Rev Immunol 2005, 23:4 I5-445.

24. Buday L: Membrane-targeting of signalling molecules by $\mathrm{SH}_{2} /$ SH3 domain-containing adaptor proteins. Biochim Biophys Acta 1999, I 422(2): 187-204.

25. Grunewald TG, Kammerer U, Kapp M, Eck M, Dietl J, Butt E, Honig $A$ : Nuclear localization and cytosolic overexpression of LASP-I correlates with tumor size and nodal-positivity of human breast carcinoma. BMC Cancer 2007, 7(I): 198.

26. Haag M: Interaktionspartner von Pro-Interleukin- 16. In Faculty of Biology Berlin , FU-Berlin; 2007.

27. $L i$ B, Zhuang $L$, Trueb $B$ : Zyxin interacts with the SH3 domains of the cytoskeletal proteins LIM-nebulette and Lasp-I. J Biol Chem 2004, 279( I 9):2040I-204I0.

28. Viney RL, Morrison AA, van den Heuvel LP, Ni L, Mathieson PW, Saleem MA, Ladomery MR: A proteomic investigation of glomerular podocytes from a Denys-Drash syndrome patient with a mutation in the Wilms tumour suppressor gene WTI. Proteomics 2007, 7(5):804-8I5.

29. Katoh $M$, Katoh $M$ : Identification and characterization of LASP2 gene in silico. Int J Mol Med 2003, I 2(3):405-4I0.

30. Terasaki AG, Suzuki H, Nishioka T, Matsuzawa E, Katsuki M, Nakagawa $\mathrm{H}$, Miyamoto S, Ohashi K: A novel LIM and SH3 protein (lasp-2) highly expressing in chicken brain. Biochem Biophys Res Commun 2004, 3 I 3(I):48-54.
31. Beckerle MC: Zyxin: zinc fingers at sites of cell adhesion. Bioessays 1997, I (1 (I):949-957.

32. Terasaki AG, Hiruta J, Suzuki J, Sakamoto S, Nishioka T, Suzuki H, Ohashi K, Azumi K, Ogasawara M: A lasp family protein of Ciona intestinalis. Biochim Biophys Acta 2007.

33. Terasaki AG, Suzuki H, Ando J, Matsuda Y, Ohashi K: Chromosomal assignment of LASP I and LASP2 genes and organization of the LASP2 gene in chicken. Cytogenet Genome Res 2006, I I 2(I-2): | $4|-| 47$

34. Schreiber V, Masson R, Linares JL, Mattei MG, Tomasetto C, Rio MC: Chromosomal assignment and expression pattern of the murine Lasp-I gene. Gene 1998, 207(2):17I-175.

35. Kleiter N, Artner I, Gmachl N, Ghaffari-Tabrizi N, Kratochwil K: Mutagenic transgene insertion into a region of high gene density and multiple linkage disruptions on mouse chromosome I I. Cytogenet Genome Res 2002, 97( I-2): 100-105.

36. Sun HJ, Bahk YY, Choi YR, Shim JH, Han SH, Lee JW: A proteomic analysis during serial subculture and osteogenic differentiation of human mesenchymal stem cell. J Orthop Res 2006, 24(I I):2059-207I.

37. Zieseniss A, Terasaki AG, Gregorio CC: Lasp-2 expression, localization, and ligand interactions: A new Z-disc scaffolding protein. Cell Motil Cytoskeleton 2008, 65(I):59-72.

38. Grunewald TG, Kammerer U, Schulze E, Schindler D, Honig A, Zimmer M, Butt E: Silencing of LASP-I influences zyxin localization, inhibits proliferation and reduces migration in breast cancer cells. Exp Cell Res 2006, 3 I 2(7):974-982.

39. Grunewald TG, Kammerer U, Winkler C, Schindler D, Sickmann A, Honig A, Butt E: Overexpression of LASP-I mediates migration and proliferation of human ovarian cancer cells and influences zyxin localisation. Br J Cancer 2007, 96(2):296-305.

40. Phillips GR, Anderson TR, Florens L, Gudas C, Magda G, Yates JR 3rd, Colman DR: Actin-binding proteins in a postsynaptic preparation: Lasp- $I$ is a component of central nervous system synapses and dendritic spines. J Neurosci Res 2004, 78(I):38-48.

4I. Li K, Hornshaw MP, van Minnen J, Smalla KH, Gundelfinger ED, Smit $A B$ : Organelle proteomics of rat synaptic proteins: correlation-profiling by isotope-coded affinity tagging in conjunction with liquid chromatography-tandem mass spectrometry to reveal post-synaptic density specific proteins. J Proteome Res 2005, 4(3):725-733.

42. Stone JL, Merriman B, Cantor RM, Geschwind DH, Nelson SF: High density SNP association study of a major autism linkage region on chromosome 17. Hum Mol Genet 2007, I6(6):704-7I5.

43. Sommer S, Hunzinger C, Schillo S, Klemm M, Biefang-Arndt K, Schwall G, Putter S, Hoelzer K, Schroer K, Stegmann W, Schrattenholz A: Molecular analysis of homocysteic acid-induced neuronal stress. J Proteome Res 2004, 3(3):572-58I.

44. Chen L, Maures TJ, Jin H, Huo JS, Rabbani SA, Schwartz J, Carter-Su C: SH2B I beta\} (SH2-B $\{$ beta\}) ENHANCES EXPRESSION OF A SUBSET OF NERVE GROWTH FACTOR-REGU. LATED GENES IMPORTANT FOR NEURONAL DIFFERENTIATION INCLUDING GENES ENCODING UPAR AND MMP3/I 0. Mol Endocrinol 2007.

45. Suchyta SP, Sipkovsky S, Halgren RG, Kruska R, Elftman M, WeberNielsen M, Vandehaar MJ, Xiao L, Tempelman RJ, Coussens PM: Bovine mammary gene expression profiling using a cDNA microarray enhanced for mammary-specific transcripts. Physiol Genomics 2003, I6( I):8-18.

46. Laux H, Tomer R, Mader MT, Smida J, Budczies J, Kappler R, Hahn H, Blochinger M, Schnitzbauer U, Eckardt-Schupp F, Hofler H, Becker KF: Tumor-associated E-cadherin mutations do not induce Wnt target gene expression, but affect E-cadherin repressors. Lab lnvest 2004, 84(I0): 1372-1386.

47. Laux: Der Einfluß von E-Cadherin und des Zellkontaktes auf das Genexpressionsprofil von MDA-MB-435S Zellen. In Faculty of Biology, LMU Munich Munich , LMU Munich; 2006.

48. Katoh $M$, Katoh M: WNT signaling pathway and stem cell signaling network. Clin Cancer Res 2007, I 3( I 4):4042-4045.

49. Loughran G, Huigsloot M, Kiely PA, Smith LM, Floyd S, Ayllon V O'Connor R: Gene expression profiles in cells transformed by overexpression of the IGF-I receptor. Oncogene 2005, 24(40):6|85-6| 93

50. Asaka S, Fujimoto T, Akaishi J, Ogawa K, Onda M: Genetic prognostic index influences patient outcome for node-positive breast cancer. Surg Today 2006, 36(9):793-80I. 
5I. Strehl S, Konig M, Meyer C, Schneider B, Harbott J, Jager U, von Bergh AR, Loncarevic IF, Jarosova M, Schmidt HH, Moore SD, Marschalek R, Haas OA: Molecular dissection of $t(I I ; I 7)$ in acute myeloid leukemia reveals a variety of gene fusions with heterogeneous fusion transcripts and multiple splice variants. Genes Chromosomes Cancer 2006, 45( I I): 104I-1049.

52. Strehl S, Borkhardt A, Slany R, Fuchs UE, Konig M, Haas OA: The human LASPI gene is fused to MLL in an acute myeloid leukemia with $t(1 / ; \mid 7)(q 23 ; q 2 I)$ Oncogene 2003 22(I): $157-160$.

53. Ingram WJ, Wicking CA, Grimmond SM, Forrest AR, Wainwright BJ: Novel genes regulated by Sonic Hedgehog in pluripotent mesenchymal cells. Oncogene 2002, 2 I (53):8I96-8205

54. Wetmore C: Sonic hedgehog in normal and neoplastic proliferation: insight gained from human tumors and animal models. Curr Opin Genet Dev 2003, I3(I):34-42.

55. Kadrmas JL, Beckerle MC: The LIM domain: from the cytoskeleton to the nucleus. Nat Rev Mol Cell Biol 2004, 5( I I):920-93I.

56. Petit MM, Crombez KR, Vervenne HB, Weyns N, Van de Ven WJ: The tumor suppressor Scrib selectively interacts with specific members of the zyxin family of proteins. FEBS Lett 2005 , 579(22):506I-5068.

57. Petit MM, Meulemans SM, Van de Ven WJ: The focal adhesion and nuclear targeting capacity of the LIM-containing lipoma-preferred partner (LPP) protein. I Biol Chem 2003 278(4):2। $57-2 \mid 68$.

58. Wang Y, Tetko IV, Hall MA, Frank E, Facius A, Mayer KF, Mewes HW: Gene selection from microarray data for cancer classification--a machine learning approach. Comput Biol Chem 2005, 29(1):37-46

59. Wang Y, Gilmore TD: Zyxin and paxillin proteins: focal adhesion plaque LIM domain proteins go nuclear. Biochim Biophys Acta 2003, 1593(2-3): II5-120.

60. Griffith E, Coutts AS, Black DM: RNAi knockdown of the focal adhesion protein TES reveals its role in actin stress fibre organisation. Cell Motil Cytoskeleton 2005, 60(3): I 40-I52.

61. Cattaruzza M, Lattrich C, Hecker M: Focal adhesion protein zyxin is a mechanosensitive modulator of gene expression in vascular smooth muscle cells. Hypertension 2004, 43(4):726-730.

62. Hoffman LM, Jensen CC, Kloeker S, Wang CL, Yoshigi M, Beckerle MC: Genetic ablation of zyxin causes Mena/VASP mislocalization, increased motility, and deficits in actin remodeling. Cell Biol 2006, I72(5):77I-782.

63. Drees BE, Andrews KM, Beckerle MC: Molecular dissection of zyxin function reveals its involvement in cell motility. I Cell Biol 1999, I47(7): 1549-1560.

64. Nix DA, Fradelizi J, Bockholt S, Menichi B, Louvard D, Friederich E, Beckerle MC: Targeting of zyxin to sites of actin membrane interaction and to the nucleus. J Biol Chem 200I, 276(37):34759-34767.

65. Hirota T, Morisaki T, Nishiyama Y, Marumoto T, Tada K, Hara T, Masuko N, Inagaki M, Hatakeyama K, Saya $\mathrm{H}$ : Zyxin, a regulator of actin filament assembly, targets the mitotic apparatus by interacting with h-warts/LATS I tumor suppressor. J Cell Biol 2000, I49(5): 1073-1086.

66. lida S, Hirota T, Morisaki T, Marumoto T, Hara T, Kuninaka S, Honda S, Kosai K, Kawasuji M, Pallas DC, Saya H: Tumor suppressor WARTS ensures genomic integrity by regulating both mitotic progression and $\mathbf{G}$ t tetraploidy checkpoint function. Oncogene 2004, 23(3I):5266-5274.

67. Amsellem V, Kryszke MH, Hervy M, Subra F, Athman R, Leh H, Brachet-Ducos C, Auclair C: The actin cytoskeleton-associated protein zyxin acts as a tumor suppressor in Ewing tumor cells. Exp Cell Res 2005, 304(2):443-456.

68. Wilson KC, Center DM, Cruikshank WW: The effect of interleukin- 16 and its precursor on T lymphocyte activation and growth. Growth Factors 2004, 22(2):97-104.

69. Benmerah A, Scott M, Poupon V, Marullo S: Nuclear functions for plasma membrane-associated proteins? Traffic 2003, 4(8):503-5। I.

70. Lopez-Diaz L, Hinkle KL, Jain RN, Zavros Y, Brunkan CS, Keeley T, Eaton KA, Merchant JL, Chew CS, Samuelson LC: Parietal cell hyperstimulation and autoimmune gastritis in cholera toxin transgenic mice. Am J Physiol Gastrointest Liver Physiol 2006, 290(5):G970-9.
7I. Li Z, Szabolcs M, Terwilliger JD, Efstratiadis A: Prostatic intraepithelial neoplasia and adenocarcinoma in mice expressing a probasin-Neu oncogenic transgene. Carcinogenesis 2006, 27(5): 1054-1067.

72. Shell SA: Regulation of the 64-kDa subunit of cleavage stimulatory factor activity in macrophage and B-lymphocyte mRNA 3'-end processing. In Faculty of School of Medicine Volume Doctor of Philosophy. University of Pittsburgh; 2005:152.

73. Chen H, Ordog T, Chen J, Young DL, Bardsley MR, Redelman D, Ward SM, Sanders KM: Differential gene expression in functional classes of interstitial cells of Cajal in murine small intestine. Physiol Genomics 2007, 3 I (3):492-509.

74. Brown AL, Wilkinson CR, Waterman SR, Kok CH, Salerno DG, Diakiw SM, Reynolds B, Scott HS, Tsykin A, Glonek GF, Goodall GJ, Solomon PJ, Gonda TJ, D'Andrea RJ: Genetic regulators of myelopoiesis and leukemic signaling identified by gene profiling and linear modeling. J Leukoc Biol 2006, 80(2):433-447.

75. Knoth S: Regulation der Genexpression bei der erythroiden Differenzierung. In Naturwissenschaftlich-Mathematische-Gesamtfakultät Volume Dr. rer.-nat.. Heidelberg , Ruprecht-Karls-Universität Heidelberg/Germany; 2006: 130.

76. Suzuki T, Tazoe H, Taguchi K, Koyama Y, Ichikawa H, Hayakawa S, Munakata $\mathrm{H}$, Isemura M: DNA microarray analysis of changes in gene expression induced by 1,25-dihydroxyvitamin D3 in human promyelocytic leukemia HL-60 cells. Biomed Res 2006, 27(3):99-109.

77. Lucas B, Grigo K, Erdmann S, Lausen J, Klein-Hitpass L, Ryffel GU: HNF4alpha reduces proliferation of kidney cells and affects genes deregulated in renal cell carcinoma. Oncogene 2005, 24(42):6418-6431.

78. Orsetti B, Nugoli M, Cervera N, Lasorsa L, Chuchana P, Ursule L, Nguyen C, Redon R, du Manoir S, Rodriguez C, Theillet C: Genomic and expression profiling of chromosome 17 in breast cancer reveals complex patterns of alterations and novel candidate genes. Cancer Res 2004, 64( I 8):6453-6460.

79. Hauck SM, Suppmann S, Ueffing M: Proteomic profiling of primary retinal Muller glia cells reveals a shift in expression patterns upon adaptation to in vitro conditions. Glia 2003, 44(3):25I-263.

80. Nelovkov A, Sutt S, Raud S, Vasar E, Koks S: Screen for genes in periaqueductal grey of male Wistar rats related to reduced exploratory activity in the elevated plus-maze. Behav Brain Res 2007, I 83(I):8-I7.

8I. Magnusson NE, Larsen A, Rungby J, Kruhoffer M, Orntoft TF, Stoltenberg M: Gene expression changes induced by bismuth in a macrophage cell line. Cell Tissue Res 2005, 32 I(2): 195-210.

82. Waage-Baudet H, Dunty WC Jr., Dehart DB, Hiller S, Sulik KK: Immunohistochemical and microarray analyses of a mouse model for the smith-lemli-opitz syndrome. Dev Neurosci 2005, 27(6):378-396.

83. Oakes SR, Robertson FG, Kench JG, Gardiner-Garden M, Wand MP, Green JE, Ormandy CJ: Loss of mammary epithelial prolactin receptor delays tumor formation by reducing cell proliferation in low-grade preinvasive lesions. Oncogene 2007, 26(4):543-553.

84. Boiko AD, Porteous S, Razorenova OV, Krivokrysenko VI, Williams $B R$, Gudkov AV: A systematic search for downstream mediators of tumor suppressor function of $\mathrm{p} 53$ reveals a major role of BTG2 in suppression of Ras-induced transformation. Genes Dev 2006, 20(2):236-252

85. Joos H, Albrecht W, Laufer S, Reichel H, Brenner RE: IL-I beta Regulates FHL2 and other Cytoskeleton Related Genes in Human Chondrocytes. Mol Med 2008.

86. Davies FE, Dring AM, Li C, Rawstron AC, Shammas MA, O'Connor SM, Fenton JA, Hideshima T, Chauhan D, Tai IT, Robinson E, Auclair D, Rees K, Gonzalez D, Ashcroft AJ, Dasgupta R, Mitsiades C, Mitsiades N, Chen LB, Wong WH, Munshi NC, Morgan G], Anderson KC: Insights into the multistep transformation of MGUS to myeloma using microarray expression analysis. Blood 2003, I 02(I3):4504-45II. 